RU Знания и навыки в системе подготовки научно-педагогических кадров в аспирантуре США

Куликова Ю. Н., Куц А. В.

Аннотация. Цель исследования - выявить специфику знаний и навыков в системе подготовки научно-педагогических кадров в аспирантуре США. В статье проясняется роль и функциональные обязанности фэкулти-девелоперов (faculty-developer) как ведущих координаторов и помощников, оказывающих профессиональную поддержку научно-педагогическим кадрам в аспирантуре США. На основе исследования аутентичной литературы на иностранном языке авторами определены и охарактеризованы базовые знания и навыки, которыми должны овладеть научно-педагогические кадры в процессе своего обучения в аспирантуре. Научная новизна исследования заключается в том, что впервые введены в научный оборот новые и оригинальные англоязычные материалы, расширяющие и дополняющие научные представления о системе подготовки аспирантов за рубежом. Авторы определили направления координационной работы для совершенствования образовательной или научно-исследовательской деятельности аспирантов; выявили знания и навыки, необходимые аспирантам для успешного завершения обучения в США; представили рекомендации по оптимизации процесса обучения аспирантов в плане его содержания.

\title{
Knowledge and Skills
}

\section{in the System of Training Scientific-Pedagogical Personnel in the USA Postgraduate Studies}

Kulikova J. N., Kuts A. V.

\begin{abstract}
The paper aims to reveal the specificity of knowledge and skills in the system of training scientificpedagogical personnel in the USA postgraduate studies. The article clarifies the role and functional responsibilities of faculty-developers as the leading coordinators and helpers who provide professional support to scientific-pedagogical personnel in the USA postgraduate studies. On the basis of research of authentic literature in the foreign language, the authors have defined and characterized the basic knowledge and skills which scientific-pedagogical personnel have to acquire during their postgraduate studies. The scientific originality of the research lies in the fact that it has introduced new and original English materials which expand and complement scientific ideas about the training system of postgraduate students abroad into scientific circulation for the first time. The authors have identified the directions of coordination work to improve the educational and research activity of postgraduate students; revealed the knowledge and skills necessary for postgraduate students to successfully complete their studies in the USA; introduced recommendations for optimization of postgraduate students' learning process in terms of its content.
\end{abstract}

\section{Введение}

Актуальность темы исследования обусловлена тем, что подготовка научно-педагогических кадров (НПК) высшей квалификации лежит в основе создания научного потенциала страны, что отражается на конкурентоспособности кадров, а также качестве проводимых научных исследований и получаемых результатов. Проблема качественной подготовки НПК в ведущих университетах и научных центрах имеет на сегодня решающее значение для прогрессивной динамики страны. Так, тезис о необходимости развития системы эффективного воспроизводства высокопрофессиональных кадров научно-образовательной сферы и повышение их конкурентоспособности на мировом уровне декларируется в содержании Федеральной целевой программы «Научные и научно-педагогические кадры инновационной России» на 2014-2020 гг. (Об утверждении федеральной целевой программы..., 2013). Акцент делается на том, что действующие механизмы развития кадрового потенциала 
научной и научно-образовательной сфер нуждаются в дополнении новыми средствами поддержки действенного воспроизводства, мобильности, интеграции НПК в мировую среду посредством повышения их квалификации до уровня, соответствующего инновационной экономике и современным международным требованиям.

Так, отечественные исследователи А. М. Марголин и Р. М. Мельников (2018) полагают, что в последние годы и процесс подготовки аспирантов, и получаемые результаты диссертационных исследований, в особенности по общественным наукам, подвергаются весьма жёсткой критике, что формирует вполне определенные негативные предпосылки для снижения мотивации к занятию наукой даже у тех молодых исследователей, которые имеют соответствующие способности и условия. Более того, согласно ученым, пропадают стимулы к работе с аспирантами и у потенциальных научных руководителей (с. 9). Согласно другому ученому, С. Д. Резнику (2015), данные факты говорят о необходимости усиления подготовки аспирантов к научно-исследовательской деятельности, повышения преемственности образовательных программ высшего образования (с. 106).

В связи с этим совершенствование процесса эффективной подготовки НПК в аспирантуре в отечественной практике обусловливает необходимость обращения к зарубежному опыту организации и содержания системы подготовки НПК в аспирантуре с целью его конструктивного использования.

Для достижения поставленной цели следует решить следующие задачи:

определить направления координационной работы с целью приобретения знаний и навыков для совершенствования образовательной или научной (научно-исследовательской) деятельности аспирантов и достижения ими карьерных перспектив;

- выявить знания и навыки, необходимые аспирантам для успешного завершения обучения в США.

Методы исследования: теоретические (анализ и синтез, обобщение и систематизация, сравнение, ранжирование) и исторической науки (ретроспективный анализ, изучение разноплановых историко-педагогических источников). Системный подход обеспечивает аналитическое описание рассматриваемой проблемы, а герменевтический подход является ведущим при работе с аутентичной литературой на иностранном языке.

Теоретической базой исследования послужили труды зарубежных авторов, в которых рассматриваются вопросы, касающиеся системы подготовки научно-педагогических кадров в аспирантуре в США (A Guide to Faculty Development..., 2010; Baughman, 2012; Border, Hoene, 2010; Filomeno, Brown, 2021; Golde, Dore, 2008; Verma, Nazzar, Fogel, 2019, Lunde, 2021).

Практическая значимость работы заключается в том, что выявленная специфика и предложенные рекомендации по оптимизации процесса обучения аспирантов могут быть полезны при разработке программ подготовки научно-педагогических кадров в современной отечественной высшей школе.

\section{Направления координационной работы с целью приобретения знаний и навыков для совершенствования образовательной или научной (научно-исследовательской) деятельности аспирантов и достижения ими карьерных перспектив}

Согласно Глену Хамильтону и Джеймсу Брауну (Hamilton, Brown, 2004), «профессиональное развитие научно-педагогических кадров» (faculty development, staff development, professional development) определяется как организованный, целенаправленный процесс, нацеленный на обеспечение устойчивого развития карьеры. Неотъемлемой частью этого процесса является приобретение знаний и навыков, которые позволяют вносить значимый вклад в совершенствование определенной сферы деятельности: образовательной или научной (научно-исследовательской). Этот процесс требует внимания к теоретическим знаниям и практическим навыкам, личным качествам и четким целям.

Так, в США координацию процесса приобретения знаний и навыков с целью совершенствования образовательной или научно-исследовательской деятельности аспирантов и достижения карьерных перспектив осуществляют фэкулти-девелоперы (faculty-developer) или наставники.

Можно выделить следующие направления координационной работы наставников с целью профессионального НПК в аспирантуре США: работают в большей степени исключительно в исследовательских университетах; сотрудничают с преподавателями вуза, вовлеченными в реализацию базовых программ обучения НПК в аспирантуре в США; оперативно и своевременно взаимодействуют с аспирантами и деканами факультета, чтобы быть в курсе проблем в сфере высшего образования; работают с большим количеством аспирантов, групп аспирантов и отделами подготовки и дополнительной подготовки аспирантов; владеют информацией о ресурсах и финансировании, доступных для подготовки НПК в аспирантуре; поскольку аспиранты являются новичками, фэкулти-девелоперы инструктируют, направляют, консультируют и наставляют их, учитывая индивидуальные специфические потребности развития и карьерного роста (A Guide to Faculty Development..., 2010).

Так, именно фэкулти-девелоперы были инициаторами организации первого собрания, которое предшествовало конференции, посвященной специфике знаний и навыков для овладения в процессе подготовки научно-педагогических кадров в аспирантуре США, и состоялось в 2007 году под эгидой «Сети профессионального и организационного развития высшего образования» (POD - Professional Development Network) (Border, Hoene, 2010). Последующие встречи стали регулярными и постоянными. Международный консорциум по развитию образования поддержал данную инициативу и актуализировал необходимость специальной поддержки как аспирантов, так и наставников, помогающей им в построении профессиональной деятельности.

Таким образом, фэкулти-девелоперы являются своего рода кураторами и консультантами аспирантов и помогают им оперативно и мобильно решать возникающие в процессе обучения в аспирантуре вопросы во всех 
сферах деятельности кроме научной. Такой подход видится актуальным и обоснованным в связи с тем, что он призван «разгрузить» отдел аспирантуры и научных руководителей аспирантов от «второстепенных» вопросов. Это позволяет преподавателям и аспирантам концентрироваться только на научном поиске, что положительно влияет на качество и результативность диссертационного исследования.

\section{Знания и навыки, которыми должны овладеть научно-педагогические кадры в процессе обучения в аспирантуре в США}

Основываясь на работах зарубежных исследователей (A Guide to Faculty Development..., 2010; Baughman, 2012; Border, Hoene, 2010; Filomeno, Brown, 2021; Golde, Dore, 2008; Verma, Nazzar, Fogel, 2019, Lunde, 2021), можно выделить одиннадцать базовых знаний и навыков, которыми должны овладеть НПК в процессе своего обучения в аспирантуре.

1. Академические навыки управления и лидерства. Дополнительная подготовка НПК в аспирантуре США, как правило, осуществляется или в специализированных центрах дополнительного образования, или на базе отдела высшей школы, который непосредственно занимается подготовкой научно-педагогических кадров в аспирантуре. Аспиранты, решая свои индивидуально-профессиональные задачи, не всегда в состоянии активно участвовать в решении сложных проблем вуза, факультета, кафедры, не способны демонстрировать социальную активность, брать на себя ответственность, проявлять инициативу, то есть не обнаруживают лидерских качеств. Новые целевые установки высшего образования, новые формы интеграции науки, образования и производства, растущие потребности в специалистах с высоким уровнем профессиональной компетенции требуют изменений в содержании и структуре подготовки НПК высшей школы (Литвинова, 2014).

В этой связи необходимой является помощь фэкулти-девелоперов в актуализации академических навыков управления и лидерства у аспирантов. Так, фэкулти-девелоперы с целью организации эффективной помощи аспирантам должны быть знакомы с: миссией и культурой кампуса, в котором обучается аспирант; администрацией, которой они подчиняются; процессом разработки и принятия управленческих решений и наиболее конструктивным способом повлиять на него, если у аспирантов появляются перспективные предложения, которые следует закрепить локальными актами вуза. Основными источниками по данному вопросу являются нормативно-правовые локальные документы - руководства (handbooks).

Таким образом, наставники помогают аспирантам развивать навыки управления и лидерства (внутри кафедры или в масштабах всего вуза) в том числе в построении программы обучения как своей, так и обучаемых аспирантами студентов. В то же время фэкулти-девелоперам необходимо быть в курсе и нести ответственность за реализацию политики вузов, касающейся таких областей, как дискриминация и плагиат, «чистота» исследования, академическая честность и Закон об американцах-инвалидах (ADA), направляя и помогая научно-педагогическим кадрам в процессе обучения в аспирантуре понять и успешно реализовать на практике сущностные характеристики политики вуза и установленных в высшей школе стандартов. Например, в Калифорнийском университете в Беркли программы подготовки НПК в аспирантуре включают в себя онлайн-курс «Профессиональные стандарты и этика в обучении» (около 1300 аспирантов изучают этот курс ежегодно) (What Good Mentoring..., 2021).

2. Знание актуальной информации о специфике образования в стране и за рубежом. Во многих странах мира системы образования реформируются в целях обеспечения соответствия новым требованиям рынка труда и социально-экономическим условиям. В целом идет движение от узкого понимания системы образования как совокупности организаций к более широкому, включающему также педагогических работников, самих обучающихся и их родителей. При такой трактовке системы образования можно говорить уже не просто о возможности изменения образовательных траекторий обучающихся, но и об их индивидуализации (Положихина, 2018, с. 251-252). В плане индивидуализации и персонифицированной помощи во многих вопросах, включая актуальную информацию о специфике образования в стране (США) и за рубежом, также предоставляют фэкулти-девелоперы.

Аспиранты должны владеть актуальной информацией относительно состояния и сущности всех уровней образования в США и за рубежом, потому что нынешние аспиранты будут искать работу в различных образовательных институтах и в различных условиях. Так как все большее количество программ подготовки НПК в аспирантуре приобретают общие черты в мировом масштабе, у аспирантов появляются разнообразные возможности для более детального знакомства с фактическим содержанием деятельности преподавателей в своей стране и за рубежом с помощью наставника (Baughman, 2012).

3. Педагогические знания. Профессор Н. М. Колычев (2013) утверждает, что на практике среди успешно закончивших аспирантуру есть определенная группа тех, кто, по различным причинам, дальше наукой самостоятельно заниматься не собирается, но хотел бы стать хорошим преподавателем. Согласимся с мнением ученого, что для успешной преподавательской работой на благо родного университета аспирантам необходимо совершенствовать свои знания в области педагогического мастерства (с. 169), так как большая часть аспирантов непедагогического или негуманитарного профиля не в полной мере владеет педагогическими знаниями, необходимыми для организации учебного процесса со студентами после окончания аспирантуры уже в качестве преподавателя.

В начале обучения по любой программе подготовки НПК в аспирантуре не следует ожидать от аспирантов того, что они сразу станут экспертами более чем в одной дисциплинарной области. Наиболее важно в первую 
очередь сконцентрироваться на получении фундаментальной базы по каждой изучаемой в аспирантуре дисциплине, которая затем будет помогать при обучении на последующих курсах в аспирантуре, написании и защите диссертации, поступлении в докторантуру, а также получении академической должности.

Освоение содержания программ подготовки НПК в аспирантуре США заключается в том, чтобы «пережить опыт» и апробировать на практике то, что описано в теории в книгах. Если наставники в действительности стремятся помочь своим подопечным аспирантам и выстроить с ними доверительные отношения, они должны быть готовы дать своевременный совет относительно того, как и где эффективнее всего будет для аспирантов апробировать и практически применить полученные ими теоретические знания. В качестве эффективного подхода можно опираться на опыт обучения в магистратуре, которую не так давно окончил аспирант (педагогическое содержание знаний). В данном случае наставники должны информировать о содержании процесса обучения аспирантов в вузе, вмешиваясь только тогда, когда это действительно необходимо. С данной целью организуются семинары по учебным дисциплинам с использованием специальных педагогических методов, характерных для каждой конкретной области знания, а не общедисциплинарные (A Guide to Faculty Development..., 2010).

4. Консультационные навыки. Аспиранты в процессе подготовки должны овладеть навыком консультирования, потому что им предстоит в будущем консультировать по различным вопросам своих студентов и аспирантов младших курсов; консультирование может быть организовано через обсуждение, беседы, индивидуальные или групповые консультации, в то время как наставник будет за ним наблюдать или осуществлять видеозапись. Аспирант должен уметь заранее определять способ консультаций, который отвечает потребностям консультируемого им студента, например, модель личностного роста, ориентированная на преподавателя, или модель структурированной обратной связи (Lunde, 2021). Важным результатом консультации является знакомство аспирантов с инструментами и навыками саморефлексии, которые им необходимо совершенствовать на практике в течение как текущего учебного года, так и на протяжении всей своей академической карьеры.

5. Навыки владения технологиями обучения и преподавания. Данный вопрос является важным для аспирантов, готовящихся к академической карьере. Они должны совершенствовать навыки владения образовательными технологиями посредством сотрудничества с центром образовательных технологий в кампусе или с помощью опытных преподавателей, которые эффективно интегрировали образовательные технологии в процесс своей работы. «Встраивание» образовательных технологий в программу обучения НПК в аспирантуре позволяет повысить эффективность их текущего обучения и будущей преподавательской деятельности.

6. Способность к обучению на различных уровнях. Основная «историческая слабость» в обучении аспирантов в США заключалась в узконаправленной подготовке аспирантов для текущего статуса в качестве начинающих преподавателей, а не для всего диапазона академических видов деятельности и преподаваемых курсов (Filomeno, Brown, 2021).

В связи с этим способность аспирантов к обучению на всех уровнях заключается в готовности координировать своих студентов как на уровне бакалавриата, так и на уровне магистратуры. Формирование у аспирантов способности преподавать студентам определенного направления подготовки на различных уровнях обучения нацелено на совершенствование профессионального мастерства аспиранта в плане: выбора разноуровневого содержания учебного материала дисциплины для бакалавров и для магистров; понимания необходимости использовать разноплановые методы, формы и средства обучения в зависимости от уровня обучения студентов (бакалавриат или магистратура); ранжирования основной и дополнительной литературы для студентов-бакалавров и студентов-магистров.

7. Знание инфраструктуры. Аспиранты будут выполнять свою работу в качестве преподавателя более эффективно, если они будут владеть знаниями о различных студенческих службах, которые обычно находятся в университетских городках. В процессе обучения у студентов возникают вопросы, решение которых возможно лишь с помощью специализированных центров: консультационный центр, академическая служба, центр поддержки студентов с ограниченными возможностями, центр для женщин, психологический центр для студентов и др. С целью успешного разрешения подобных вопросов аспирант должен быть хорошо знаком с инфраструктурой кампуса и миссией каждого из организованных на его территории центров. Некоторые программы подготовки научно-педагогических кадров в аспирантуре США Университета НебраскиЛинкольна и Университета Беркли в Калифорнии, например, предлагают семинары или интерактивные театральные проекты, направленные на решение конфликтов, предотвращение психологических проблем, дискриминации (Lunde, 2021; What Good Mentoring..., 2021).

8. Навыки организации исследования и представления его результатов научному сообществу. Аспиранты должны быть осведомлены о требованиях, возможностях и потенциальных ресурсах для привлечения грантов для финансирования своих исследований, а также для публикации результатов этих исследований. Аспирантам необходимо: сформулировать план исследования, определить его цель, содержание и этапы; собрать данные о ранее поддержанных проектах, близких по тематике к текущей исследовательской работе аспиранта; определить возможности публикации в журналах по исследуемой проблематике. Понимание сущности и структуры исследований предоставляет аспирантам знания и навыки для организации своих собственных исследовательских программ и будет способствовать эффективному обучению начинающих НПК в аспирантуре.

9. Навыки управления персоналом и навыки финансового менеджмента. В зависимости от карьерных перспектив аспирантам после завершения своего обучения в аспирантуре представляется возможность занимать административные должности, которые сопряжены с управлением персоналом и контролем полной или частичной академической или неакадемической карьеры сотрудников. В результате аспиранты должны быть осведомлены о кадровой политике вуза и развивать навыки менеджмента персонала. 
Другой вид менеджмента, необходимый аспиранту, - финансовый. Главной стратегической целью финансового менеджмента является повышение благосостояния собственников организации в текущей и долгосрочной перспективе (Андреев, 2016, с. 5). В какой степени корректным является вопрос о финансовом менеджменте в вузе? Практика финансовой деятельности вузов такова, что значительная часть бюджета формируется за счет доходов от внебюджетной деятельности - оказания платных образовательных и других услуг. Для многих учреждений доля заработанных средств превышает бюджетное финансирование, а это даже для среднего по численности вуза весьма значительные суммы, распоряжение которыми требует профессионализма (Клюев, 2000). Стимулом в этом направлении служит усиление конкурентных преимуществ вуза посредством предложения на рынке равного с конкурентами качества образовательных услуг, но по более низким ценам, или предоставление большего объема услуг при равных с конкурентами затратах, тем самым увеличивая входящий поток финансовых ресурсов (Гринь, 2016, с. 18).

Таким образом, аспирант, который занимает административную должность, должен уметь не только эффективно распоряжаться финансовыми ресурсами, если это входит в его обязанности, но и контролировать качество предоставляемых платных услуг подведомственных ему сотрудников.

10. Знание неакадемических карьерных перспектив. С. Гольд и Т. Дор (Golde, Dore, 2008) в своей научной работе «Разные цели: опыт докторантуры» (“At cross purposes: What the experiences of doctoral students reveal about doctoral education”) указали на необходимость подготовки аспирантов к должностям вне вуза, потому что эффективность обучения научно-педагогических кадров зависит от их готовности к любой карьере, используя возможность взаимодействовать с представителями государственных и региональных структур. Такое сотрудничество позволяет сохранить обратную связь с выпускниками-аспирантами, которые добились успеха в неакадемической карьере и могут поделиться своим опытом с аспирантами.

11. Дополнительные знания с целью совершенствования в профессиональной сфере. Аспирантура была и остается основным институтом подготовки кадров высшей научной квалификации. В то же время этот институт развивается в соответствии с запросами общества (Бережная, Гуртов, 2017, с. 58), которые направлены на подготовку востребованных, мобильных и квалифицированных специалистов. Так, с целью постоянного повышения своей квалификации и актуализации полученных знаний по учебным дисциплинам аспиранты должны быть хорошо знакомы с инновациями и современными достижениями по исследуемой ими проблематике. Для достижения данной цели в США аспиранты постоянно взаимодействуют с коллегами внутри страны и за рубежом, состоят в ассоциациях профессионального развития, участвуют в международных образовательных программах по обмену НПК для обучения за рубежом, организуют междисциплинарные проекты различного уровня - от локального до международного.

Таким образом, можно сформулировать предложения по оптимизации обучения аспирантов в современной отечественной высшей школе: личностно значимая направленность подготовки научно-педагогических кадров в аспирантуре; самостоятельность аспирантов в процессе обучения для решения профессионально значимых задач; наличие обратной связи в лице фэкулти-девелоперов для выявления затруднений и путей их преодоления в процессе обучения в аспирантуре; использование личностно-приемлемых действий для профессионального развития в долгосрочной перспективе; опора на индивидуальный опыт; ориентированность в большей мере на достижение конкретных задач, чем на предмет в целом; оперативность применения полученных знаний; развитие коммуникативных, лидерских и информационных компетенций.

\section{Заключение}

Делая вывод, следует отметить, что в координационную работу с целью приобретения знаний и навыков для совершенствования образовательной или научно-исследовательской деятельности аспирантов и достижения ими карьерных перспектив осуществляют наставники (фэкулти-девелоперы). Направления их работы заключаются в выстраивании сотрудничества не только с аспирантами, но и с деканами, преподавателями вуза, отделами подготовки и дополнительной подготовки аспирантов, чтобы оперативно и своевременно решать возникающие вопросы и быть в курсе актуальных изменений в сфере высшего образования.

В отношении знаний и навыков, которыми должны овладеть НПК в процессе обучения в аспирантуре в США, среди знаний следует назвать: знание актуальной информации о специфике образования в стране и за рубежом; педагогические знания; знание инфраструктур; знание неакадемических карьерных перспектив; знание дополнительных возможностей для совершенствования в профессиональной сфере. В свою очередь к навыкам относятся: академические навыки управления и лидерства; консультационные навыки; навыки владения технологиями обучения и преподавания; способность к обучению на различных уровнях; навыки организации исследования и представления его результатов научному сообществу; навыки управления персоналом и навыки финансового менеджмента. Анализ выявленных знаний и навыков позволяет сделать вывод, что обучение аспирантов в США направлено в первую очередь на повышение эффективности их подготовки к самостоятельной научной и педагогической деятельности после окончания обучения, а также на подготовку аспирантов к профессиональной деятельности в конкурентной среде рыночной экономики.

Перспективы дальнейшего исследования проблемы мы видим в исследовании специфики знаний и навыков в системе подготовки НПК в аспирантуре в других зарубежных странах, выявлении и тиражировании положительного и конструктивного опыта, определении возможных рекомендаций по оптимизации отечественного процесса обучения аспирантов. 


\section{Источники | References}

1. Андреев В. И. Финансовый менеджмент. Саратов, 2016.

2. Бережная Ю. Н., Гуртов В. А. Аспирантура в новых реалиях // Университетское управление: практика и анализ. 2017. Т. 21. № 3.

3. Гринь А. М. Предметная область финансового менеджмента // Университетское управление: практика и анализ. 2016. № 104 (4).

4. Клюев А. К. Организация финансового менеджмента в вузе // Университетское управление. 2000. № 4 (15).

5. Колычев Н. М. Аспирантам нужна педагогическая подготовка // Омский научный Вестник. 2013. № 3 (119).

6. Литвинова К. В. Психологические условия развития профессионально значимых лидерских качеств аспирантов - будущих преподавателей вуза: дисс. ... к. пед. н. Ставрополь, 2014.

7. Марголин А. М., Мельников Р. М. Пути повышения эффективности подготовки аспирантов // Высшее образование в России. 2018. Т. 27. № 12.

8. Об утверждении федеральной целевой программы «Научные и научно-педагогические кадры инновационной России» на 2014-2020 годы и внесении изменений в данную программу на 2009-2013 года. 2013. URL: http://government.ru/docs/2056/

9. Положихина М. А. Тенденция развития образования в России и за рубежом (Обзор) // Социальные и гуманитарные науки: отечественная и зарубежная литература. Серия 2: Экономика. 2018. № 3.

10. Резник С. Д. Аспирантура: как повысить эффективность // Университетское управление: практика и анализ. 2015. № 4 (98).

11. A Guide to Faculty Development. 2nd ed. / ed. by K. J. Gillespie, D. L. Robertson, W. H. Bergquist. San Francisco: Jossey-Bass, 2010.

12. Baughman J. Student professional development: Competency-based learning and assessment in an undergraduate industrial technology course. 2012. URL: https://lib.dr.iastate.edu/etd/12592

13. Border L. B., Hoene L. M. von. Graduate and professional student development programs // A Guide to Faculty Development. 2nd ed. / ed. by K. J. Gillespie, D. L. Robertson, W. H. Bergquist. San Francisco: Jossey-Bass, 2010.

14. Filomeno F. A., Brown C. Immigrant students and global education // Journal of Global Education and Research. 2021. Vol. 6. Issue 2 (2022).

15. Golde C. M., Dore T. M. At cross purposes: what the experiences of doctoral students reveal about doctoral education: a report prepared for the Pew Charitable Trusts. 2008. URL: http://www.phd-survey.org

16. Hamilton G. C., Brown J. E. Faculty Development: What Is Faculty Development? // Academic Emergency Medicine. 2004. Vol. 10. Issue 12.

17. Lunde J. P. 101 Things You Can Do in the First Three Weeks of Class. 2021. URL: https://www.unl.edu/gradstudies/ professional-development/first-3-weeks

18. Verma R., Nazzar S., Fogel J. Mental and Physical Health of Physicians Undergoing Postgraduate Training in the USA: A Single Center Study // International Journal of Medical Science and Current Research (IJMSCR). 2019. Vol. 2. Issue 4.

19. What Good Mentoring Looks Like to a First-Time GSI. 2021. URL: https://gsi.berkeley.edu/faculty-departments/ teaching-with-gsis/mentoring-first-time-gsis/

\section{Информация об авторах | Author information}

RU Куликова Юлия Николаевна ${ }^{1}$, к. пед. н.

Куц Анна Вячеславовна ${ }^{2}$, к. пед. н.

${ }^{1}$ Пензенский государственный аграрный университет

2 Пензенский государственный университет

EN Kulikova Julia Nikolaevna ${ }^{1}, \mathrm{PhD}$

Kuts Anna Vyacheslavovna ${ }^{2}, \mathrm{PhD}$

${ }^{1}$ Penza State Agrarian University

${ }^{2}$ Penza State University

${ }^{1}$ kulikova.y.n@pgau.ru, ${ }^{2}$ kuts_a.v@mail.ru

\section{Информация о статье | About this article}

Дата поступления рукописи (received): 03.10.2021; опубликовано (published): 28.12.2021.

Ключевые слова (keywords): знания; навыки; система подготовки; научно-педагогические кадры; аспирантура США; knowledge; skills; training system; scientific-pedagogical personnel; USA postgraduate studies. 